Reconstructed skeleton of an $\mathbf{8 5}$ millionyear-old plesiosaur, the fossilized bones of which were found near Tokyo in 1968.

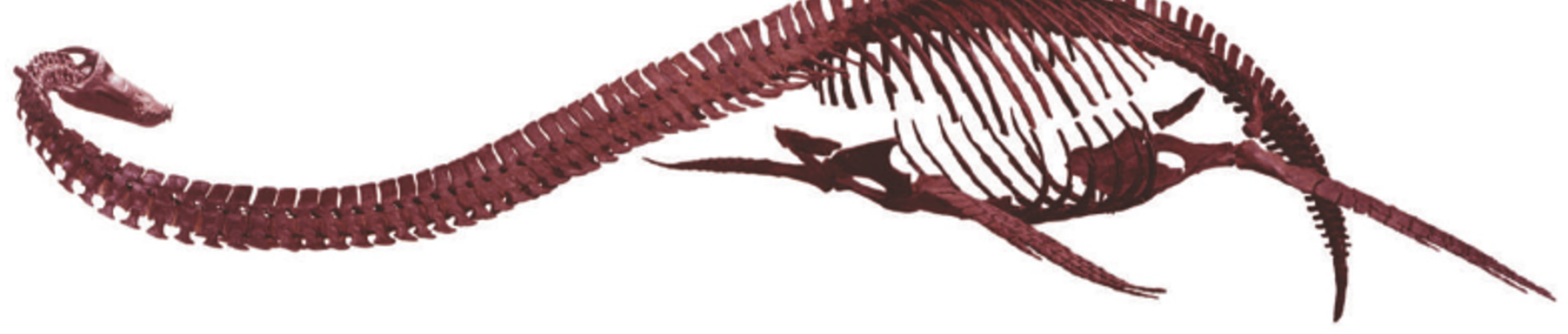

\title{
Teenager waits 40 years for recognition
}

TOKYO

Tadashi Suzuki was a fossil-mad high-school student when he discovered some ancient bones in a riverbank near his home. He wrote to a local palaeontologist about them, thinking he might have discovered a plesiosaur.

That was in 1968. Almost four decades later, his find has finally been confirmed as a new species. Although the time taken in this case is extreme, experts say it highlights the problems many palaeontologists face in raising the funds to characterize and classify new discoveries.

Suzuki, now 54, says he has been fascinated by fossils since his childhood. When he was 17 , he read about a fossil plesiosaur - a longnecked reptile that flourished in the world's oceans during the Cretaceous era - being found in his home town of Iwaki City, about 200 kilometres north of Tokyo. "I thought I could find another, he says. He went down to the same riverbank and discovered more bones.

Rather than disturb the fossils, he wrote to Ikuo Obata, a palaeontologist in Tokyo, to tell him about the find. Obata's colleague Yoshikazu Kasegawa took on the project.

It took about seven years to excavate the fossil bones, dean them up and assemble them into a three-metre-long plesiosaur skeleton, which is around $70 \%$ complete. Hasegawa believed Suzuki's find to be a new species, but research then slowed almost to a halt.

Proving that a specimen is a new species requires comparing it to all other known specimens and showing it is sufficiently different. Hasegawa, now head of the Gunma Museum of Natural History, says he couldn't afford all the relevant references as well as travel to foreign museums and libraries. The project finally took off in 2003, when Tamaki Sato joined the team. A researcher at the National Science Museum in Tokyo, she had studied plesiosaurs in Canada and had data from other specimens.

The paper describing Suzuki's plesiosaur as a new species was finally published this month (T. Sato, Y. Hasegawa and M. Manabe Palaeontology 49, 467-484; 2006). ${ }^{\alpha}$ I am delighted to see the research published," says Suzuki, now chief researcher at his local ammonite centre. "I think the 38 years were inevitable."

The team has called it Futabasaurus suzukii and reports that it is an elasmosaur, the main type of plesiosaur. Elasmosaurs lived all over the world, but few specimens from Asia have been

well preserved. The Japanese find is 85 million years old, the oldest specimen in the northern Pacific confirmed to be an elasmosaur.

Plesiosaurs have been little studied compared with other species groups that were around at the time, such as dinosaurs and invertebrates. Many details, such as how they swam, remain a mystery (see 'Mystery and myth behind the plesiosaur'). "It's a nice addi-

"Large vertebrate fossils are seen as high profile, but this rarely results in money for study and display." tion to the story of plesiosaurs," says Leslie Noé, a specialist in ancient reptiles at the University of Cambridge's Sedgwick Museum in Britain. "New plesiosaurs give us a unique insight into the biodiversity of the Cretaceous seas."

Noé says it would take about five years to get a fossil find classified if researchers had sufficient time, money and personnel. But the situation faced by Hasegawa and his colleagues will sound familiar to many palaeontologists, who find it increasingly difficult to get funds, he adds. "Large fossil vertebrates are seen as high profile by the public, but this rarely results in the money required to study and display the specimens becoming available." Ichiko Fuyuno

\section{Mystery and myth behind the plesiosaur}

When the ancestors of plesiosaurs abandoned land for water more than 215 million years ago, they gave their descendants an unusual mechanism of propulsion. Almost all other known water-dwellers use a tail to move, but these reptiles swam by flapping or rotating flipper-like appendages that evolved from what were previously limbs. The exact mechanism is still the subject of debate.

Larger plesiosaurs grew to more than 10 metres in length, making them the biggest aquatic animals of the time. Theirlong, flexible necks and strong jaws are thought to have been used to pluck fish from passingshoals. But that picture is being reconsidered following the publication last year of a plesiosaur fossil that had remains of bottom-dwelling creatures, such as crustaceans, in its stomach (see C. R. McHenry, A. G. Cook and S. Wroe Science 310, 75; 2005).
The reptiles are also a candidate for unfounded butpopular theories that their descendants surviveto this day. Scientists dismissed claims that a Japanese trawler had caught a decaying plesiosaur in the late 1970 s and the Scottish press sometimes links plesiosaurs with the Loch Ness monster. Jim Giles 